Cover Letter

Is the biopsychosocial model in musculoskeletal physiotherapy adequate?

\title{
An Evolutionary Concept Analysis
}

\author{
Primary author \\ Georgi Daluiso-King
}

Professional Discipline

MSK Physiotherapy

Current appointment

Advanced Practitioner in Physiotherapy specialising in hip, knee and spinal pathology

MMACP Mentor

University of Brighton visiting lecturer

\section{Degree}

Msc Neuromusculoskeletal Physiotherapy, MMACP

\section{Address and email}

Horsham Hospital, Physiotherapy MSK Department, Hurst Road, Horsham, RH12 2DR

georgi.daluiso@nhs.net 


\section{Second author \\ Dr Clair Hebron}

\section{Professional Discipline}

MSK Physiotherapy, Academic and Clinical

\section{Current appointment}

Principal lecturer and course leader for MSc Musculoskeletal Physiotherapy, University of Brighton

Private Physiotherapist -'Physiotherapy at the Leaf'

\section{Degree}

$\mathrm{PhD}, \mathrm{MMACP}$

\section{Address and email}

School of Health Sciences, University of Brighton, 49 Darley Road, Eastbourne, BN20 7YR

c.l.hebron@brighton.ac.uk 


\section{ABSTRACT}

Purpose: It is considered that implementation of the biopsychosocial model (BPSM) within physiotherapy is affected by its lack of conceptual clarity. This concept analysis explores the meaning and offers conceptual transparency to the BPSM and expands upon its current conceptual framework for practice.

Method: Literature was selected through a systematic search. The studies were analysed and the data themed following 'thematic analysis'.

Results: From the seventeen articles included, five master themes and four subthemes were constructed. The master themes were: 'Bio-medical', 'Psychological', 'Social factors', 'Communication' and 'Individualised Care'. The subthemes were: 'Education', 'Cognitive', 'Behavioural', 'Occupational factors' and 'Therapeutic Alliance'.

Conclusion: A contemporary visual representation of the BPSM is presented which represents a holistic, humanist perspective. 'Communication' scaffolds the framework and supports the exploration of the person's lifeworld through the 'therapeutic alliance'.

Keywords: biopsychosocial model; biopsychosocial approach; physiotherapy; conceptual; philosophy; concept analysis; holistic; humanist. 


\section{Is the biopsychosocial model in musculoskeletal physiotherapy adequate?}

\section{An Evolutionary Concept Analysis}

\section{Introduction}

Traditionally healthcare has operated within a biomedical model (BMM) of care. This dualistic ${ }^{1}$ model, which focuses on biological factors and views the mind and body as disconnected, has proven inadequate at addressing the complexity of pain and disability. It has at worst been accused of exacerbating conditions, such as non-specific low back pain (Butler, Evans, Greaves \& Simpson, 2004; Killick and Davenport, 2014; Waddell and Burton, 2005). Awareness of the insufficiency of the BMM in health occurred alongside developments in psychological and sociocultural understanding, such as in how an association between social class and risk of disease was recognised (Syme and Bermkan 1976), and the social determinant of health model was developed (Marmot et al, 1991). An understanding of psychosocial factors 'revolutionised' management of persons with low back pain (LBP) disability, where LBP became recognised as an illness rather than a biological disease (Waddell, 2004; Waddell, McCulloch, Kummel, Venner, 1980; Waddell, 1987). These evolutionary understandings within healthcare challenged mind-body dualism and offered support for an alternative medical model (Malone and Garcia-Penagos, 2014; Samelson, 1981). The biopsychosocial model (BPSM) offered an alternative conceptual framework that facilitated a way of engaging health professions in the dynamic and co-existence of the biological, psychological and social branches of ill-health, and the interplay between these (Engel 1979 and 1978).

Over the last three decades pain science research has reinforced the BPSM, where connections between beliefs, emotions and the central nervous system, pain and disability have been further explored and discovered (Gifford, 1998; Lumley et al, 2011; Moseley and Butler, 2015). In physiotherapy, the mature organism model was developed to help both physiotherapists and persons experiencing pain reach a broader biological and psychosocial understanding of 
impairment (Gifford, 1998a). Addressing these bio-psycho-social factors can be found to positively impact upon health outcomes, drawing healthcare further away from the biomedical model (BMM) (Lumley et al, 2011; Moseley, Nicholas, Hodges, 2004) towards the alternative BPSM, where the values of humanism² and scientism ${ }^{3}$ are proposedly intertwined (Brosschot, 2017; Coronado and Bialosky, 2017; Deyo, 2015; Lotze, 2015).

Through the evolution of the BPSM, alongside greater recognition of the importance of improving an individual's health autonomy and agency, contemporary literature suggests a philosophical shift in how health professionals understand, approach and support impairment (Delany, Fryer and van Kessel, 2015; Evans, Lucas and Kerry, 2017; Holopainen et al, 2018; Low, 2017; Mehta, 2011). This has created a 'person centered approach' paradigm underpinned by holism ${ }^{4}$. Literature recognises that through skilled enquiry the clinician is able to step into the world of the individual, embrace the person's lived experience and begin to understand their unique lifeworld ${ }^{5}$ and the tapestry of their health condition (Dahlberg, Todres and Galvin, 2009; Jones, Edwards and Gifford, 2002; Langendoen, 2004; Solvang and Fougner, 2016). It is the multiplicity of these lifeworld influences, how they intertwine and are interpreted in a clinical reasoning process, which forms the foundations of the BPSM in practice.

However, although the sentiments of the BPSM are holistic, it has been suggested that the way this model is conceptualised by some physiotherapists oversimplifies health, in a similar way to the BMM (Butler, Evans, Greaves, Simpson, 2004; Coronado and Bialosky, 2017; Wallden, 2015). The complexity of physiotherapy could be seen as reduced by the BPSM to the biological, psychological and sociological, making it philosophically reductionist ${ }^{6}$ and pluralist $^{7}$ (Butler, Evans, Greaves and Simpson, 2004). This conceptualisation of the BPSM encourages compartmentalised thinking and is reflected in empirical research, highlighting the challenges for physiotherapists attempting to operationalise a holistic approach (Baldwin, 2008; Oostendorp et al, 2015; 
Sanders, Foster, Bishop and Ong, 2013; Singla, Jones, Edwards and Kumar, 2015). Many factors influence conceptualisation and application of the model; education and training, traditional structures of healthcare systems and sociocultural factors, the nature of the clinician and their individual life experiences, which creates diversity between practitioners (Bientzle, Cress, and Kimmerle, 2014; Jones, Edwards and Gifford, 2002; Nijs et al, 2013; Oostendorp et al, 2015; Staub and Vollhardt, 2008). Thus, a lack of clarity in conceptualisation of the BPSM may affect implementation and its ability to evolve, indirectly impeding the growth of person centered holistic care within musculoskeletal physiotherapy (Cronin, Ryan and Coughlan, 2010; Rodgers, 1989). The aim of our research is to clarify this conceptual understanding of the BPSM within musculoskeletal physiotherapy, in order to understand its meaning and use in clinical practice.

\section{Methodology}

This study employed concept analysis methodology (Rodgers, 1989; Rodgers and Knafl, 2000) in order to seek clarification of how the BPSM is conceptualised in the physiotherapy literature. Concepts - such as the BPSM - are represented as ideas that can be formed and changed through the use of words within a particular community. Within concept analysis, these 'words' are known as 'attributes', which when utilised can alter a concept's meaning and application over time, rather like the children's game of 'Chinese whispers', where meaning can become 'lost or changed in translation' between people over time (Rodgers and Knafl, 2000; Weaver and Mitcham, 2008).

A concept analysis aims to enhance understanding of the influences that precede ('antecedents') and resulted from ('consequences') the concept's existence. An exploration of the antecedents, consequences and attributes could offer clarity to the conceptualisation of the BPSM and illuminate a greater understanding of its evolution. Conceptual clarity would provide transparency to a universal definition of the BPSM and gives grounding for further conceptual growth and development 
of the concept (Baldwin, 2008; Risjord, 2008). The acceptance of changes occurring to concepts over time, introduces an 'evolutionary' epistemological ${ }^{8}$ view and thus the 'evolutionary method' of concept analysis was used to clarify how the BPSM is conceptualised in musculoskeletal physiotherapy.

\section{Method}

The evolutionary concept analysis 'method' follows a number of steps listed below (Rodgers and Knafl, 2000; Tofthagen and Fagerstrøm, 2010). Phases 1-3 are discussed within this section and phase 4-5 within the Findings and Discussion sections.

1. Identify the concept of interest and associated terms (surrogate terms).

2. Identify and select an appropriate realm (setting and sample) for data collection.

3. Collect data relevant to identify antecedents, consequences and attributes (Table 1 for definitions).

4. Analyse the data of each of these areas separately.

5. Identify implications for current and future practice and research.

The surrogate terms (words that are used interchangeably with BSPM) were identified by a preliminary search on the MEDLINE database via PubMed using the search terms 'biopsychosocial' AND 'physiotherapy'. Terms that occurred regularly in abstracts were classified as 'surrogate terms' (Table 2). Next, these terms proceeded to become the key words used within a systematic literature search. A further comprehensive database search using the surrogate terms (Table 2) was performed through combining these keywords with 'physiotherapy' and 'physical therapy'. Truncations ('*') and Boolean terms 'AND' were added when using MEDLINE through PubMed, CINHAL, Embase via Ovid, AMED and Cochrane. An iterative 'snowballing' search strategy was chosen and limited to the most recent five years (2012 - 2017). This search had an efficient strategy of focusing on selecting contemporary literature that would offer a 'current' 
conceptual viewpoint of the BPSM in musculoskeletal physiotherapy (Greenhalgh and Peacock, 2005; Jesus, Bright, Kayes and Cottl, 2016; Rodgers and Knafl, 2000). The snowballing method involved four search phases. These are referred to as the 'Primary', 'Secondary', 'Tertiary' and 'Quaternary' database searches. At each phase, the reference lists of all the selected articles were manually reviewed. If titles of articles in the reference list reflected the surrogate/ key terms these were added to the list of identified articles (Figure 1).

The titles and abstracts of all identified articles were screened against the eligibility criteria (Table 3 ). In cases where contextual significance to the BSPM within physiotherapy was unclear, the full article text was reviewed and screened by the author and another reviewer (both Advanced Musculoskeletal Physiotherapy Practitioners). If article suitability remained ambiguous, the article was included.

\section{Data Analysis}

An inductive thematic analysis as proposed by Braun and Clarke (2006) guided the process of clustering BPSM antecedents, consequences and attributes (Table 4). The selected articles were reviewed and re-reviewed to allow for full emersion of the conceptualisation of BPSM within the selected literature. Reoccurring ideas, words and descriptions used in reference to the antecedents, consequences and attributes of the BPSM were highlighted, coded and grouped. Together these grouped data items offer a formalised grounding of why and how the BPSM came about (antecedents); the effect that its evolution has had on health and healthcare (consequences); and what is actually meant by the term 'BPSM' (attributes). The grouped data items form the findings of the analysis and are presented as themes. To support methodological understanding and transparency, an extract from the data that constructed the antecedent theme 'failure of biomedical model' is shown in Table 5. 


\section{Findings}

An overview of the antecedents, consequences and attribute themes identified in the literature are summarised in Figure 2. Single words, phrases and direct quotations from the salient literature have been used within the following sections to highlight how the themes and sub-themes (Figure 2) are conceptualised in musculoskeletal physiotherapy.

\section{Antecedent Themes (what preceded the BPSM)}

Antecedents set the scene and explain the reasoning behind why the BPSM evolved within musculoskeletal physiotherapy. The analysed literature defined three main themes that explained how the BMM was inadequate at managing musculoskeletal conditions and that a more person-focused approach was necessary. This led to the development of national and international guidelines to support a cultural shift within physiotherapy practice. These will be further discussed below.

\section{Failure of the Biomedical Model (BMM)}

There was a consensus that the nature of pain and disability is multi-dimensional and cannot be explained through the BMM alone (Sanders, Foster, Bishop and Ong, 2013; Synnott et al, 2016). This evidence concedes that the BMM is ineffective and adherence to the BMM in physiotherapy MSK practice is a risk factor for 'long-term sick-leave' and 'iatrogenic effects' consequentially affecting poor outcomes (Domenech et al, 2011; Nijs et al, 2013; Oostendorp et al, 2015):

"An excessively biomedical style of undergraduate training can increase negative beliefs and attitudes about LBP (low back pain)" (Domenach et al, 2011).

\section{Literature and supporting guidelines}

The selected BPSM literature discusses an awareness of how LBP, disability and persistent pain complaints are referred to as conditions that require the individual's psychological (cognitive) and social perspectives to include effective 
treatments, which highlights a shift in physiotherapy practice (Foster and Delitto, 2011; Langendoen, 2004; Nijs et al, 2013; Oostendorp et al, 2016; Sanders, Foster, Bishop and Ong, 2013; Singla, Jones, Edwards and Kumar, 2015; van Erp et al, 2016). The literature referred to three guidelines recognising the need for an 'integrated approach' by addressing biomedical, personal and environmental factors in order to reduce pain and disability. The guidelines were the National Institute for Health and Care Excellence (NICE), the guideline for LBP, the World Health Organization (WHO) for the International Classification of Functioning (ICF) guideline and the chronic LBP (CLBP) treatment guidelines, (Foster and Delitto, 2011; Langendoen, 2004; Oostendorp et al, 2015; Sanders, Foster, Bishop and Ong, 2013; Singla, Jones, Edwards and Kumar, 2015; Solvang and Fougner, 2016).

\section{Cultural change in physiotherapy}

There was a consensus of the data confirming the association of psychosocial considerations on pain and disability with an emphasis on 'patients' rights' and involvement in their health (Langendoen, 2004). This increased autonomy over one's health raised an awareness of the need to embrace a cultural change within physiotherapy and a paradigm shift from a 'practitioner-centred' to 'patientcentred' approach (Cowell et al, 2016; Foster and Delitto, 2011; Singla, Jones, Edwards and Kumar, 2015; Solvang and Fougner, 2016):

"Patient-centredness is considered to be the practical application of the multidimensional bio-psychosocial illness model" (Langendoen, 2004)

\section{Attribute Themes (the characteristics of the model)}

The attributes identified in the literature highlight that the characteristics of the model are predominantly conceptualised in line with the motel's pluralist name, with three of the 5 master themes being the major components of this model (biomedical, psychological, social). However, the other two master themes, 
communication and individualised care, reveal conceptualisation that goes beyond this reductionist perspective.

\section{Biomedical}

The biomedical aspect of the BPSM was described as involving a "comprehensive, systematic, appropriate, valid and tailored functional assessment to analyse disabilities... and impairments" (Foster and Delitto, 2011; Jones, Edwards and Gifford, 2002; Langendoen, 2004). The data infers that the BPSM encapsulates a diagnostic reasoning approach through placing an emphasis on the 'physical assessment' and drawing on 'clinical reasoning', substantiating an informed 'diagnosis' to be made (Figure 3) (Nijs et al, 2013; Oostendorp et al, 2017; Solvang and Fougner, 2016; Synnott et al, 2016; van Erp et al, 2016; Wijma, van Wilgen, Meeus and Nijs, 2016). These objective factors highlight the importance of establishing the physical characteristics of health, and that "the biopsychosocial model should not be used to ignore biomedical factors" (Nijs et al, 2013).

However, the biomedical focus was commonly discussed with an emphasis on the 'holistic' influences over pain:

"the therapist needs to assess causes, physical and non-physical contributing factors and mechanisms (psychosocial and socio-economic factors) that seem to play a role in the overall clinical presentation" (Langendoen, 2004).

A myriad of connections were consistently drawn between the biomedical characteristics of the BPSM and the other themes within this analysis. These connections propose an inability to separate the intertwined nature of the physical with the psychological and social, and suggest how the BPSM represents an integrated approach: 
"the biopsychosocial model implies integrated clinical reasoning with respect to biological as well as psychological and social factors" (Nijs et al, 2013).

Treatment modalities were discussed predominantly around 'chronic pain' and 'low back pain' (LBP) (Domenech et al, 2011; Foster and Delitto, 2011; Nijs et al, 2013; Oostendorp et al, 2017; Singla, Jones, Edwards and Kumar, 2015; van Erp et al, 2016; Wijma, van Wilgen, Meeus and Nijs, 2016). This is suggestive of how there is a lack of research reflecting the use of the BPSM in regards to the treatment of acute pain, pain in other areas of the body, or in disability. However, treatments in relation to the BPSM ranged from 'hands-on' therapy to 'exercise' prescription, and incorporating a 'graded activity' focus that was based around 'patient-specific goals' (Figure 3).

\section{Sub-theme education}

'Education' was referred to as a type of treatment modality that frequently described education on pain physiology and aspects of 'health promotion' to support the individual gaining a greater comprehension of their condition (Figure 2). There was an emphasis on customising the language, depth of information and style of teaching to ensure information is transferred to the individual (Cowell et al, 2016; Jones, Edwards and Gifford, 2002):

"information addressing pain perceptions and coping strategies should be used by the therapist to tailor the individual education sessions" (Nijs et al, 2013).

For information to be meaningful to the individual, the literature recognized the importance of helping the person to know themselves through exploring the biomedical, psychological and social factors with an emphasis on the ability to individualise and translate this therapeutically (Jones, Edwards and Gifford, 2002; Nijs et al, 2013; Oostendorp et al, 2017; Solvang and Fougner, 2016; Wijma, van Wilgen, Meeus and Nijs, 2016): 
"communicative teaching... Here the intent is to foster insight in our patient with regard to the factors which may be contributing to the ongoing production of pain" (Jones, Edwards and Gifford, 2002).

\section{Psychological factors}

The theme 'psychological factors' was present in the data in descriptions of people's 'feelings' and 'emotions', such as 'anxiety', 'fear' and 'depression' that reflected a key element to the BPSM (Wijma, van Wilgen, Meeus and Nijs, 2016) (Figure 3). The literature described psychological factors as inseparable from the individual's experiences, behaviours and cognitions (Langeodeon, 2004; Synnott et al, 2016; Wijma, van Wilgen, Meeus and Nijs, 2016). Although behavioural and cognitive factors are represented as sub-themes for the presentation of theming the data, in the literature they were understood as symbiotic with the individual's psychology.

The BPSM literature frequently discussed the importance of physiotherapists recognising the uniqueness of the person's health experience, with an emphasis on an ability to enquire into the emotive influences on wellbeing:

'Managing patients' problems also requires the understanding of their unique pain or illness experience (... by making enquiries about ... their understanding, beliefs, feelings and coping strategies)" (Jones, Edwards and Gifford, 2002).

Operationalising this enquiry is difficult and communication was discussed as an important feature that enabled a personal exploration (Figure 6). This highlights the binding force that communication has between the master themes of the BPSM (biomedical, psychological, social and individualised care), (Duncan, Bishop and Foster, 2016; Sanders, Foster, Bishop and Ong, 2013; Solvang and Fougner, 2016; Synnott et al, 2016; van Erp, et al 2016): 
"an open communication style promoted an easiness and fluidity in the exploration of the cognitive, psychological and social dimensions with patients" (Synnott et al, 2016).

\section{Sub-theme - behavioural factors}

The BPSM literature in musculoskeletal physiotherapy recognised the involvement of behavioural factors within pain and their exploration as a key aspect of the model (Figure 4). There was an awareness of behavioural influences over 'patient engagement', linking to the 'motivation' of the individual and their 'attitude' and 'readiness' to change (Jones, Edwards and Gifford, 2012; Foster and Delitto, 2011; Nijs et al, 2013; van Erp et al, 2016). Further behaviours such as 'catastrophising' and 'fear avoidance' are discussed within the literature as consequences of misaligned beliefs and emotions responding to these beliefs, highlighting the influence of psychological and cognitive factors over behaviour (Domenech et al, 2011; Foster and Delitto, 2011; Jones, Edwards and Gifford, 2002; Nijs et al, 2013; Sanders, Foster, Bishop and Ong, 2013; Solvang and Fougner, 2016; Synnott et al, 2016; Wijma, van Wilgen, Meeus and Nijs, 2016). Consequentially, these negative behaviours were perceived to contribute to the development of particular 'coping strategies' and may affect the 'patient's engagement' within musculoskeletal physiotherapy:

"Negative illness perceptions ...are associated with maladaptive illness behaviour, dysfunctioning, poor treatment adherence and treatment outcome" (Nijs et al, 2013).

\section{Sub-theme - cognitive factors}

Cognitive factors were commonly referenced in regards to the 'beliefs', 'expectations' and 'illness perceptions' of the individual (Figure 4). They are discussed with an emphasis towards 're-conceptualising negative thoughts' through "understanding and interacting with patients and their belief systems" (Jones, Edwards and Gifford, 2002). There was consensus within the data that 
the BPSM encapsulates the ability of the clinician to step into the cognitive world of the individual, to see the world through their lens and to further understand the relationships and influences these have on the individual's behavioural and psychological expressions (Foster and Delitto, 2011; Jones, Edwards and Gifford, 2002; Langendoen, 2004; Nijs et al 2013; Sanders, Foster, Bishop and Ong, 2016; Solvang and Fougner, 2016; Synott et al, 2016):

"When patients encounter physiotherapists who engage with their lifeworld, they report feelings of being heard" (Solvang and Fougner, 2016).

\section{Social factors}

The literature discusses social factors as essential characteristics of the BPSM, recognising the influence that the social and physical environment can have on health (Solvang and Fougner, 2016). The existence of cultural diversities, 'family' and 'friendships' are identified as characteristics within a person's community that can shape an individual's response to illness, and impact upon how they may perceive and interact with pain and disability (Figure 5) (Foster and Delitto, 2011; Nijs et al, 2013; Sanders, Foster, Bishop and Ong, 2013; Solvang and Fougner, 2016; Synnott et al, 2016; van Erp et al, 2016):

"the cultural, family and work circumstances (e.g. support, cohesion, control and efficacy, security and autonomy) together influence their (patients') thoughts, behaviours and their biomedical health condition" (Singla, Jones, Edwards and Kumar, 2015).

\section{Sub-theme - occupational factors}

The data frequently made reference to 'job satisfaction', 'socio-economic' status, 'unemployment' and the psychological consequences of these occupational factors such as anxiety and depression (Figure 5). These consequences may influence 'illness-perceptions' and behavioural responses to pain (Nijs et al, 
2013; Sanders, Foster, Bishop and Ong, 2013; Synnott et al, 2016; Wijma, van Wilgen, Meeus and Nijs, 2016).

\section{Communication}

Communication was discussed as a key feature of the BPSM and regarded as a channel that enables 'patient-centred' management by connecting to the beliefs of the individual:

"forms of communication that are more personal in order to gain greater insights into the thoughts and beliefs of their patients" (Solvang and Fougner, 2016).

Communication was discussed as a key feature of the BPSM and regarded as a channel that enables 'patient-centered' management by connecting to the beliefs of the individual and cultivating 'forms of communication that are more personal in order to gain greater insights into the thoughts and beliefs of their patients' (Solvang and Fougner, 2016).

Ways of embracing this were emphasised through discussing an awareness of the specifics of 'language' used by the therapist; focusing on 'reassurance' and an 'empathetic' dialogue (Figure 6), that is intuitive and flexible in accordance with the individual (Cowell et al, 2016; Jones, Edwards and Gifford, 2002; Langendoen, 2004; Solvang and Fougner, 2016):

"listening; empathy; encouragement... and simple language; ... giving patients time to discuss their story" (Synnott et al, 2016).

'Motivational interviewing' involving 'explorative' inquiry, 'open questions' and 'attentive listening' are common within the data when discussing the BPSM (Figure 6) (Foster and Delitto, 2011; Jones, Edwards and Gifford, 2002; Langendoen, 2004; Sanders, Foster, Bishop and Ong, 2013; Solvang and Founger, 2016; Synnott et al, 2016): 
"When therapists responded with a facilitating approach, using open questions, formulating a version of the patient's talk, and affirmative head nodding, then active patient participation was enhanced" (Cowell et al, 2016).

These skills were discussed as assisting in gaining 'understanding' and 'knowing of the patient' (Figure 6) (Jones, Edwards and Gifford, 2002; Langendoen, 2004). Communication was also discussed as encompassing a commitment to a 'reflective approach' within and upon the therapeutic dialogue, and an opportunity for insightful reasoning (Cowell et al, 2016; Langendoen, 2004; Nijs et al, 2013; Sanders, Foster, Bishop and Ong, 2013; Solvang and Founger, 2016; Synnott et al, 2016; Singla, Jones, Edwards and Kumar, 2015; van Erp et al, 2016; Wijma, van Wilgen, Meeus and Nijs, 2016):

"Changing the understanding and behaviour (of either therapist or patient) requires transforming existing perspectives. ...changing existing perspectives requires reflection on the basis of those perspectives or beliefs" (Jones, Edwards and Gifford, 2002).

\section{Individualised care}

In the data, the individual's pain response was described as being affected by a multitude of personal and societal influences, and this was explicitly linked to an individualised management plan, even in the presence of similar physical diagnoses (Cowell et al, 2016; Domenech et al, 2011; Langendoen, 2004; Oostendorp et al, 2017; Oostendorp et al, 2015; Sanders, Foster, Bishop and Ong, 2013; Singla, Jones, Edwards \& Kumar, 2015; Synnott et al, 2016; van Erp et al, 2016; Wijma, van Wilgen, Meeus and Nijs, 2016). IIl-health "is very much framed by the circumstances of the patient's lived life" (Solvang and Fougner, 2016), and therefore "pain or illness is shaped in part by who they are and how they and their unique system responds" (Jones, Edwards and Gifford, 2002). 
The data also presents an 'integrated', 'holistic' understanding of the complexity and uniqueness of the individual's pain experience (Figure 6), (Cowell et al, 2016; Foster and Delitto, 2011; Langendoen, 2004; Nijs et al, 2013; Oostendorp et al, 2017; Sanders, Foster, Bishop \& Ong, 2013; Solvang and Fougner, 2016; van Erp et al, 2016). Individualising care was discussed in a way that suited "a person's preferences and needs" and showed an "understanding of their viewpoint and individual pain" exploring "what really makes them tick" (Synnott et al, 2016).

\section{Sub-theme therapeutic alliance}

'Therapeutic alliance' was one of the most frequently acknowledged attributes of the BPSM. Creating a therapeutic bond is thought to facilitate a greater depth of understanding through the sharing and aligning of the individual's and therapist's thoughts, beliefs and emotions (Nijs et al, 2013; Solvang and Fougner, 2016; Wijma, van Wilgen, Meeus and Nijs, 2016):

"development and maintenance of rapport... facilitated a deeper insight into the individual cognitive and psychological drivers of pain" (Synnott et al, 2016).

Communication and individualised care were presented as intricately linked to the building of a positive therapeutic alliance, where 'mutual agreements' and respect for the patient as a person were important (Jones, Edwards and Gifford, 2002; Solvang and Fougner, 2016 Synnott et al, 2016);

"The patient is not only to be thought of as representing a set of diagnoses, but rather as an individual to be allied with whose voice is to be heard" (Solvang and Fougner, 2016).

\section{Consequence themes (what occurred as an effect of the BPSM)}

Four main consequence themes were developed that highlight how the shift towards the BPSM consequentially offered more person-centered care and 
proposed improved outcomes. However, conversely there is a recognition within the musculoskeletal physiotherapy literature that there is a failure to implement the BPSM, highlighting a training need within the profession.

\section{Improved outcomes}

The data showed how improved treatment adherence and better outcomes in 'functional, cognitive and behavioral measures' may be influenced through involving the individual more in their health. This offers a resolution to malformed 'illness perceptions', 'coping strategies' and 'movement patterns' (Cowell et al, 2016; Nijs et al, 2013; Synnott et al, 2016; van Erp et al, 2016). There is "research evidence indicating better patient outcomes when" the BPSM is "used alongside traditional physiotherapy" (Sanders, Foster, Bishop and Ong, 2013).

\section{Enhanced aspects of person-centered care (PCC)}

It was a common opinion within the data that "the practical application of the biopsychosocial illness model" is "called a patient-centred approach" (Langendoen, 2004). When the BPSM was used in a way that facilitated a deeper enquiry of an individual's health experience, there was "a greater willingness" for people/ patients "to voice their opinions", which was regarded within the literature as enhancing PCC (Foster and Delitto, 2011; Solvang and Fougner, 2016; Synnott et al, 2016). The acceptance of the 'person' rather than the person labelled as a 'diagnosis' was discussed and 'patient-centered' management presented as a consequence (Langendoen, 2004; Nijs et al, 2013; Sanders, Foster, Bishop and Ong, 2013):

"biopsychosocial assessment is required to understand the process of CS (central sensitisation) and allow an individualized, patient-centered explanation" (Wijma, van Wilgen, Meeus and Nijs, 2016).

\section{Implementation/ application failure of the BPSM in practice}


The literature discussed how there is a lack of standardisation in the use of the BPSM. Evidence from qualitative research suggests that physiotherapists felt "under-prepared" within the psychosocial elements of the model and believed "these problems fell outside of their immediate scope of practice" (Sanders, Foster, Bishop and Ong, 2013; Singla, Jones, Edwards and Kumar, 2015). This was discussed as a failure of clinicians' ability to work within a BPSM of care. The lack of time and resources available for physiotherapists to address these factors fully, as well as poor clinician adherence to guidelines and theory-based evidence, was discussed as consequentially affecting the application of the BPSM (Foster and Delitto, 2011; Langendoen, 2004). It was suggested that implementation failure was also a consequence of a lack of conceptual understanding of the BPSM (Domenech et al, 2011; Duncan, Bishop and Foster, 2015; Foster and Delitto, 2011; Singla, Jones, Edwards and Kumar, 2015). A physiotherapist's dualistic conception of the BSPM as psycho-social 'or' biological-medical is discussed as a consequence of how physiotherapists are still predominately positioned towards the BMM of care (Domenech et al, 2011; Nijs et al, 2013; Sanders, Foster, Bishop and Ong, 2013):

"participants... demonstrated an understanding of the biopsychosocial model where they saw the 'biological' and 'psychosocial' as two separate entities" (Singla, Jones, Edwards and Kumar, 2015).

\section{Training need within physiotherapy}

The data suggested that physiotherapists feel undertrained to address the psychosocial dimensions of the BPSM, and authors identified a training need focusing on these aspects of physiotherapy (Foster and Delitto, 2011; Sanders, Foster, Bishop and Ong, 2013; Solvang and Fougner, 2016). The literature discussed how the dominance of the BMM in physiotherapy inhibits the integration of the BPSM and draws this back to an insufficiency in academic and professional training (Foster and Delitto, 2011; Singla, Jones, Edwards and Kumar, 2015): 
"The high number of physical therapy students with inappropriate beliefs... has forced us to rethink the methods of training students... and to examine its biopsychosocial aspects" (Domenach et al, 2011).

\section{Discussion}

This concept analysis of the BPSM explored the model's 'antecedents' (factors that preceded the model); 'consequences' (factors that followed the model); and 'attributes' (unique characteristics of the model itself) (Table 1), and has enabled the formation of conceptual maps to offer clarity to the meaning of the BPSM in musculoskeletal physiotherapy (Figures 3, 4, 5 and 6). The discussion will primarily focus on the interconnectedness and relevance of the findings to one another and, through this, draw upon the influences this analysis has on the notional, philosophical and practical understanding of the BPSM in musculoskeletal physiotherapy.

Anteceding factors in this analysis support Engel's (1978) original purpose of the BPSM to address a 'failure of the biomedical model' in managing health, necessitating a 'cultural shift in physiotherapy (healthcare)'. 'Literature and supporting guidelines' were also an antecedent in this analysis that suggests the BMM alone is ineffective in therapeutic care. This view resonates with literature that highlights a need to address the psychosocial components of disability and ill-health to improve outcomes in various clinical scenarios including acute as well as chronic peripheral and spinal pain (Chester, Shepstone, Lewis and Jerosch, 2013; Deyo, 2015; Sanchis-Alfonso, 2015).

The BPSM has been schematically represented by three overlapping themes (biological, psychological and sociocultural), and presented as a Venn diagram to supposedly aid in facilitating a more person-focused, holistic ${ }^{9}$ practice (Figure 7). This visual representation and the title itself 'bio-psycho-social' does not align to a philosophically holistic stance, but to one that is reductionist ${ }^{10}$, where the health 
of an individual is reduced into sections that may, at times, overlap. However, as recognised by Aristotle, 'the whole is greater than the sum of the parts', yet the 'bio-pyscho-social' title and its traditional visual representation, (without the accompanying theoretical explanations), dichotomizes Engel's original holistic intentions. This traditional Venn diagram representation of the model might, in part explain the dualist ${ }^{11}$ or pluralist ${ }^{12}$ conceptions that some musculoskeletal physiotherapists have of the BPSM, where the 'biological' and 'psychosocial' can be valued as two or three separate entities (Singla, Jones, Edwards and Kumar, 2015). The struggle between the theoretical holistic nature and the pluralist, reductionist visual representation of the BPSM resonates with the findings of this study; 'implementation failure of the BPSM in practice', and a 'training need within physiotherapy' for an individualised, person-centered, holistic approach.

The consequence themes 'Implementation/ application failure of the BPSM in practice' and a 'Training need within physiotherapy', seem juxtaposed to the other consequence themes 'enhanced person-centered care (PCC)' and 'improved outcomes'. This highlights the contrasts between rhetoric and operationalization, where 'words' (theory and theoretical understanding) do not always translate into 'actions' (skill-set and behaviours) (Foster and Delitto, 2011; Sanders, Foster, Bishop and Ong, 2013). This is echoed in the findings of a study which identified discrepancies between what was observed, and how physiotherapists perceived themselves to have implemented components of the BPSM (Oostendorp et al, 2015). This suggested that there may be inconsistency between understanding and operationalising the BPSM.

Physiotherapists have described managing psychosocial factors as "out of the scope of physiotherapy practice" (Sanders, Foster, Bishop and Ong, 2013), supporting the consequence 'training need in physiotherapy'. Furthermore, contrary to psychological factors, sociocultural influences on health are not as well recognised and are theoretically and empirically underexplored in comparison, particularly to that of the biomedical aspects (Chalmers and Madden, 2019; Killick and Davenport, 2014; Lumley et al 2011). This may further 
explain 'BPSM implementation failure'. It has been proposed that the consequence of both the 'training need in physiotherapy' and 'BPSM implementation failure' can be changed by psychosocially orientated education (Sanders, Foster, Bishop and Ong, 2013). However, studies have shown that clinicians who undergo training demonstrate positive changes in their attitudes and beliefs towards pain (Domenech et al, 2011; Synnott et al, 2016), but these changes do not transfer into practice (Overmeer, Boersma, Main and Linton, 2009).

One aspect that could influence physiotherapists' ability to implement the BPSM may relate to an individual's philosophical stance. A physiotherapist who has objectivist ${ }^{13}$ philosophical leanings may naturally bias more towards the 'bio' aspects of the model, objectifying and compartmentalising the biological and the psychosocial elements as separate entities (Sanders, Foster, Bishop and Ong, 2013; Singla, Jones, Edwards and Kumar, 2015; Synnott et al, 2015). To support a change in physiotherapeutic individualised and PCC, education on the BPSM needs to consider training methods that explore philosophy, and reflect on one's own nature of reality or 'being' (ontology ${ }^{14}$ ) and how one understands the nature of knowledge (epistemology ${ }^{15}$ ). This sets foundations for the clinician to be mindful of 'their' self in the therapeutic encounter, potentially affecting how one then approaches and navigates the 'self' of another person.

The development of conceptual maps in this concept analysis (Figures 3, 4, 5 and 6) has attempted to clarify the BPSM's attributes and gain conceptual clarity. Five interconnected master themes; biomedical, psychological and social factors, communication and individualised care alongside five subthemes; education, cognitive, behavioural and occupational factors, and therapeutic alliance were identified in this study as the essence of the BPSM. This analysis has found communication and therapeutic alliance to be the binding force between the themes within the conceptual maps and Venn diagrams (Figures 3, 4, 5, 6 and 7). Exploration of the themes biomedical, education, psychological, cognitive, 
behavioural, social and occupational factors and the development of individualised care and therapeutic alliance, depend upon the clinician's communicative adaptability. Communication is vital in creating a positive therapeutic relationship which has been shown to improve outcomes and health (Besley, Kayes and McPherson, 2011; Josephson et al, 1982; Pinto et al, 2012; Roberts and Langridge, 2017 in Petty, 2017). This resonates with the consequences of the BPSM 'improved outcome' and 'enhanced person centred care (PCC)'.

'Communication' and 'education', 'individualised care' and 'therapeutic alliance' have been identified in PCC literature (Cooper, Smith and Hancock, 2008; Morgan and Yoder, 2012; Pinto et al, 2012; Wijma et al, 2017). Further connections between PCC and the BPSM are also reflected in this study's analysis of consequences, where one of the products of the BPSM was 'enhanced aspects of PCC'. This highlights the interdependence between the BPSM and PCC, echoing the model proposed by Mead and Bower, (2000) where the BPSM is seen as a key dimension of PCC.

However, the lack of skilled, adaptable communication may also explain the consequence 'implementation failure of the BPSM'. Physiotherapists' misinterpretation of an individual's needs through a lack of skilled 'language', 'listening', 'empathy' and 'understanding' have been shown to negatively affect the therapeutic alliance (Cooper, Smith and Hancock, 2008; Mudge, Stretton and Kayes, 2014), which is a consistent BPSM attribute (Duncan, Bishop and Foster, 2015).

If the main attribute themes from this analysis are displayed in the same Vennstyle diagram that has been traditionally used as a framework for practice (Figure 7 ), the BPSM would be presented as in Figure 8. This representation continues to reduce the BPSM to its basic foundations, as the process of concept analysis reduces the essential elements of the concept in order to enhance understanding 
(Regenmortel, 2004). However, within the practical management of health, reductionism ${ }^{16}$ can be inadequate as it relies heavily on the philosophy of the interpreter to build the bridges between the characteristics, and meld the (biomedical, psychological, cognitive, behavioural, social and occupational) threads back together to make a whole.

The authors believe it is important to not only remove the boundaries between the themes of the BPSM to allow for integration, but also to remove their overlap and embrace the holistic ${ }^{17}$ quality of healthcare. A proposed 'holistic framework' for practice (Figure 9) aims to represent the meeting and joining of two different lives and all that is within them (lifeworlds ${ }^{18}$ ), that of the clinician and that of the individual, through a symbiotic existence between communication and therapeutic alliance. This aims to embrace the attribute theme individualised care'. In Figure 9, the helix attempts to demonstrate the unique sequencing of the biomedical, psychological (cognitive, behavioural), social (occupational) elements of an individual's health. The helix also aims to symbolise the 'expressions' or individualised phenomena that arise from the complex interactions between these integral characteristics. Communication and therapeutic alliance are presented as the scaffold of the helix, the structure that enables the ingredients of complex, unique human experience to be explored. The partnership of an accomplished inquiry and an entrusted relationship enables the individual, their lifeworld and their experience to be understood and meaningfully supported.

This proposed holistic framework (Figure 9) is grounded upon explicit conceptual analysis of the BPSM and attempts to offer an evolved framework for practice beyond that of the BPSM, which can assist in understanding and implementing holism and individualised PCC within musculoskeletal physiotherapy.

\section{Limitations}

Although the search strategy initially sought discussion in the context of physiotherapy (irrespective of discipline), discussions in all the literature identified 
in the search were in the context of musculoskeletal physiotherapy. Therefore, these findings may not be generalisable to other contexts. Due to limited literature exploring the societal impact on pain and disability within musculoskeletal physiotherapy, it is recognised that this concept analysis potentially represents a narrower 'social' construct of the BPSM and highlights a need for further research to be focused within this area.

\section{Implications for current and future practice and research}

A reductionist ${ }^{19}$, objectivist ${ }^{20}$ view of the BPSM seems to result in its implementation in separate 'bio', 'psycho' and 'social' forms. The conceptual maps, reconstructed Venn diagrams and proposed holistic framework (Figures 3, $4,5,7,8$ and 9) aim to offer an opportunity for the model to support future training practically, alongside philosophically informed practice. This study identified communication and therapeutic alliance as the binding themes that enable the other themes within the analysis to exist. Musculoskeletal physiotherapy education should therefore support enhanced communication skills alongside an awareness of philosophy.

\section{Conclusion}

This concept analysis intends to offer notional clarity to the BPSM within musculoskeletal physiotherapy through identifying its antecedents, consequences and attributes (Table 1). The antecedents were 'Failure of the Biomedical Model', 'Literature and supporting guidelines' and 'Cultural change in physiotherapy'. The consequences were 'Improved outcomes', 'Enhanced aspects of person-centered care' and paradoxically 'Implementation/ application failure of the BPSM in practice' and 'Training need within physiotherapy'. The attributes were clustered into themes, five master themes; biomedical, psychological and social factors, communication and individualised care alongside five subthemes; education, cognitive, behavioural and occupational factors, and therapeutic alliance. 
Based on these findings a holistic ${ }^{21}$ framework for care is proposed, in which communication and the therapeutic alliance forms the scaffold for a humanistic ${ }^{22}$ approach to therapeutic care. This framework, having evolved through an evolutionary method of concept analysis reflects a holistic philosophical viewpoint to healthcare, supporting the notion that individual health is complex, unique and ever evolving. The reductionist ${ }^{23}$, pluralistic ${ }^{24}$ traditional BPSM is insufficient at representing this complexity and halts expansion towards a more person centered approach. Musculoskeletal physiotherapy needs to reconceptualise the BPSM to support holistic PCC.

\section{Declaration of Interest}

The authors report no declarations of interest.

\section{Reference List}

Baldwin, M.A. 2008, Concept analysis as a method of inquiry, Nurse Researcher 15: 49.

Besley, J., Kayes, N.M., McPherson, K.M. 2011, Assessing therapeutic relationships in physiotherapy: literature review, New Zealand Journal of Physiotherapy 39: 81.

Bialosky, J.E., Beneciuk, J.M., Bishop, M.D., Coronado, R.A., Penza, C.W., Simon, C.B. \& George, S.Z. 2018, Unraveling the Mechanisms of Manual Therapy: Modeling an Approach, The Journal of orthopaedic and sports physical therapy 48: 8-18.

Bientzle, M., Cress, U., Kimmerle, J. 2014, Epistemological beliefs and therapeutic health concepts of physiotherapy students and professionals, BMC medical education 14: 208-208. 
Braun, V., Clarke, V. 2006, Using thematic analysis in psychology, Qualitative Research in Psychology 3: 77-101.

Brosschot, J. F. 2017, Ever at the ready for events that never happen, European Journal of Psychotraumatology 8.

Butler, C.C., Evans, M., Greaves, D. \& Simpson, S. 2004, Medically Unexplained Symptoms: The Biopsychosocial Model Found Wanting, Journal of the Royal Society of Medicine 97: 219-222.

Chester, R., Shepstone, L., Lewis, J.S., Jerosch-Herold, C. 2013, Predicting response to physiotherapy treatment for musculoskeletal shoulder pain: protocol for a longitudinal cohort study, BMC musculoskeletal disorders 14:192.

Coronado, R. A., Bialosky, J. E. 2017, Manual physical therapy for chronic pain: the complex whole is greater than the sum of its parts, Journal of Manual \& Manipulative Therapy 25:115-117.

Cooper, K., Smith, B.H., Hancock, E. 2008, Patient-centredness in physiotherapy from the perspective of the chronic low back pain patient, Physiotherapy 94: 244252.

Cowell, I., McGregor, A., Murtagh, G., O'Sullivan, P., O'Sullivan, K., Poyton, R., Schoeb, V. 2016, 'What do you think is going on': Analysis of how physiotherapists' explore patients' back pain beliefs: A conversation analytic approach, Manual Therapy 25: 114-115.

Cronin, P., Ryan, F., Coughlan, M. 2010, Concept analysis in healthcare research, International Journal of Therapy and Rehabilitation 17: 62-68. 
Dahlberg, K., Todres, L., Galvin, K., Institutionen för vårdvetenskap och socialt arbete, Fakulteten för humaniora och samhällsvetenskap \& Växjö universitet 2009, Lifeworld-led healthcare is more than patient-led care: an existential view of well-being, Medicine, health care, and philosophy 12: 265-271.

Delany, C., Fryer, C. \& van Kessel, G. 2015, An ethical approach to health promotion in physiotherapy practice, Health Promotion Journal of Australia: Official Journal of Australian Association of Health Promotion Professionals 26: 255-262.

Deyo, R.A. 2015, Biopsychosocial care for chronic back pain, BMJ: British Medical Journal 350: 538-538.

Domenech, J., Sánchez-Zuriaga, D., Segura-Ortí, E., Espejo-Tort, B., Lisón, J.F. 2011, Impact of biomedical and biopsychosocial training sessions on the attitudes, beliefs, and recommendations of health care providers about low back pain: a randomised clinical trial, Pain 152: 2557-2563.

Duncan, K., Bishop, A., Foster, N. 2016, Development of a new conceptual framework for the biopsychosocial clinical approach using concept mapping methodology, Manual Therapy 25: 51-52.

Engel, G.L. 2012 (1978), The need for a new medical model: a challenge for biomedicine, Psychodynamic psychiatry 40: 377.

Engel, G.L. 1979, The biopsychosocial model and the education of health professionals, General hospital psychiatry 1: 156.

Evans, D. W., Lucas, N., Kerry, R. 2017, The form of causation in health, disease and intervention: biopsychosocial dispositionalism, conserved quantity transfers 
and dualist mechanistic chains, Medicine Health Care and Philosophy 20: 353363.

Foster, N.E., Delitto, A. 2011, Embedding Psychosocial Perspectives Within Clinical Management of Low Back Pain: Integration of Psychosocially Informed Management Principles Into Physical Therapist Practice-Challenges and Opportunities, Physical Therapy 91: 790-803.

Gifford, L. \& Physiotherapy Pain Association 1998, Topical issues in pain: science and management; Fear-avoidance beliefs and behaviour, NOI Press, Falmouth.

Greenhalgh, T., Peacock, R. 2005, Effectiveness and efficiency of search methods in systematic reviews of complex evidence: audit of primary sources, BMJ 331: 1064-1065.

Holopainen, R., Piirainen, A., Heinonen, A., Karppinen, J. \& O'Sullivan, P. 2018, From "Non-encounters" to autonomic agency. Conceptions of patients with low back pain about their encounters in the health care system, Musculoskeletal Care 16: 269-277.

Jesus, T.S., Bright, F., Kayes, N., Cott, C.A. 2016, Person-centred rehabilitation: what exactly does it mean? Protocol for a scoping review with thematic analysis towards framing the concept and practice of person-centred rehabilitation, BMJ open 6: e011959.

Jones, M., Edwards, I., Gifford, L. 2002, Conceptual models for implementing biopsychosocial theory in clinical practice, Manual Therapy 7: 2-9.

Josephson, I., Woodward-Kron, R., Delany, C., Hiller, A., Högskolan i Jönköping, Hälsohögskolan and The Jönköping Academy for Improvement of Health and 
Welfare 2015, Evaluative language in physiotherapy practice: How does it contribute to the therapeutic relationship?, Social science \& medicine (1982) 143: 128-136.

Kerry, R., Maddocks, M. \& Mumford, S. 2008, Philosophy of science and physiotherapy: An insight into practice, Physiotherapy Theory and Practice, 24: 397-407.

Killick, L. \& Davenport, T.E. 2014, Pain Worlds: Towards the Integration of a Sociocultural Perspective of Pain in Clinical Physical Therapy, Physiotherapy Research International, 19: 193-204.

Langendoen, J. 2004, The patient-centredness of evidence-based practice. A case example to discuss the clinical application of the bio-psychosocial model, Manual Therapy 9: 228-233.

Lotze, M., Moseley, G.L. 2015, Theoretical Considerations for Chronic Pain Rehabilitation, Physical therapy 95: 1316-1320.

Low, M. 2017, A novel clinical framework: The use of dispositions in clinical practice. A person centred approach, Journal of Evaluation in Clinical Practice 23: 1062-1070.

Lumley, M.A., Cohen, J.L., Borszcz, G.S., Cano, A., Radcliffe, A.M., Porter, L.S., Schubiner, H. \& Keefe, F.J. 2011, Pain and emotion: a biopsychosocial review of recent research, Journal of Clinical Psychology 67: 942-968.

Malone, J.C. \& García-Penagos, A. 2014, When a clear strong voice was needed: A retrospective review of Watson's (1924/1930) behaviorism, Society for the Experimental Analysis of Behavior, United States. 
Marmot, M.G., Smith, G.D., Stansfeld, S., Patel, C., North, F., Head, J., White, I., Brunner, E. \& Feeney, A. 1991, Health inequalities among British civil servants: the Whitehall II study, Lancet (London, England) 337: 1387.

Mead, N., Bower, P. 2000, Patient-centredness: a conceptual framework and review of the empirical literature, Social Science \& Medicine 51: 1087-1110.

Mehta, N. 2011, Mind-body Dualism: A critique from a Health Perspective, Mens sana monographs 9: 202.

Morgan, S., Yoder, L.H. 2012, A Concept Analysis of Person-Centered Care, Journal of Holistic Nursing 30: 6-15.

Moseley, G.L. \& Butler, D.S. 2015, Fifteen Years of Explaining Pain: The Past, Present, and Future, Journal of Pain: 16: 807-813.

Moseley, G.L., Nicholas, M.K. \& Hodges, P.W. 2004, A randomized controlled trial of intensive neurophysiology education in chronic low back pain, The Clinical journal of pain 20: 324 .

Mudge, S., Stretton, C., Kayes, N. 2014, Are physiotherapists comfortable with person-centred practice? An autoethnographic insight, Disability \& Rehabilitation 36: 457-463.

Nijs, J., Roussel, N., van Wilgen, C.P., Koke, A., Smeets, R. 2013, Thinking beyond muscles and joints: Therapists' and patients' attitudes and beliefs regarding chronic musculoskeletal pain are key to applying effective treatment, Manual Therapy 18: 96-102.

Oostendorp, R.A.B., Elvers, H., Mikolajewska, E., Laekeman, M., Trijffel, E.v., Samwel, H. 2017. Letter to the Editor. Clinical biopsychosocial physiotherapy 
assessment of patients with chronic pain: The first step in pain neuroscience education by Amarins J Wijma et al., 2016 33: 260-262.

Oostendorp, R.A.B., Elvers, H., Mikolajewska, E., Laekeman, M., Trijffel, E.v., Samwel, H. \& Duquet, W. 2015, Manual physical therapists' use of biopsychosocial history taking in the management of patients with back or neck pain in clinical practice, Scientific World Journal 2015: 170463.

Overmeer, T., Boersma, K., Main, C.J., Linton, S.J. 2009, Do physical therapists change their beliefs, attitudes, knowledge, skills and behaviour after a biopsychosocially orientated university course?, Journal of evaluation in clinical practice 15: 724-732.

Petty, N.J. 2017, Principles of musculoskeletal treatment and management: a handbook for therapists, Third edn, Elsevier, London.

Pinto, R.Z., Ferreira, M.L., Oliveira, V.C., Franco, M.R., Adams, R., Maher, C.G., Ferreira, P.H. 2012, Patient-centred communication is associated with positive therapeutic alliance: a systematic review, Journal of physiotherapy 58: 77-87.

Regenmortel, M.H.V.V. 2004, Reductionism and complexity in molecular biology, EMBO reports 5: 1016-1020.

Risjord, M. 2009, Rethinking concept analysis, Journal of advanced nursing 65: 684-691.

Rodgers, B., Knafl, K. 2000, Concept development in nursing. Foundations, techniques and applications, 2nd edn, Elsevier.

Rodgers, B.L. 1989, Concepts, analysis and the development of nursing knowledge: the evolutionary cycle, Journal of advanced nursing 14: 330-335. 
Samelson, F. 1981, Struggle for scientific authority: The reception of Watson's Behaviorism, 1913-1920, Journal of the History of the Behavioral Sciences 17: 399-425.

Sanchis-Alfonso, V. 2014, Holistic approach to understanding anterior knee pain. Clinical implications, Knee Surgery, Sports Traumatology, Arthroscopy 22: 22752285.

Sanders, T., Foster, N.E., Bishop, A., Ong, B.N. 2013, Biopsychosocial care and the physiotherapy encounter: physiotherapists' accounts of back pain consultations, BMC musculoskeletal disorders 14: 65-65.

Singla, M., Jones, M., Edwards, I., Kumar, S. 2015, Physiotherapists' assessment of patients' psychosocial status: Are we standing on thin ice? A qualitative descriptive study, Manual Therapy 20: 328-334.

Staub, E. \& Vollhardt, J. 2008, Altruism born of suffering: the roots of caring and helping after victimization and other trauma, The American journal of orthopsychiatry 78: 267.

Syme, S. L, Berkman, L. F. 1976, Social class, susceptibility and sickness, American Journal of Epidemiology 104: 1-8.

Solvang, P.K., Fougner, M. 2016, Professional roles in physiotherapy practice: Educating for self-management, relational matching, and coaching for everyday life, Physiotherapy Theory and Practice 32: 591-602.

Staub, E. \& Vollhardt, J. 2008, Altruism born of suffering: the roots of caring and helping after victimization and other trauma, The American journal of orthopsychiatry 78: 267. 
Synnott, A., O'Keeffe, M., Bunzli, S., Dankaerts, W., O'Sullivan, P., Robinson, K., O'Sullivan, K. 2016, Physiotherapists report improved understanding of and attitude toward the cognitive, psychological and social dimensions of chronic low back pain after Cognitive Functional Therapy training: a qualitative study, Journal of physiotherapy 62: 215-221.

Synnott, A., O'Keeffe, M., Bunzli, S., Dankaerts, W., O'Sullivan, P., O'Sullivan, K. 2015, Physiotherapists may stigmatise or feel unprepared to treat people with low back pain and psychosocial factors that influence recovery: a systematic review, Journal of physiotherapy 61: 68-76.

Tofthagen, R., Fagerstrøm, L.M. 2010, Rodgers' evolutionary concept analysis a valid method for developing knowledge in nursing science: Presentation of Rodgers' evolutionary concept analysis, Scandinavian Journal of Caring Sciences 24: 21-31.

van Erp, R.M.A., Huijnen, I.P.J., Köke, A.J.A., Abbink, F.E., den Hollander, M., Smeets, R.J.E.M. 2017; 2016; Development and content of the biopsychosocial primary care intervention 'Back on Track' for a subgroup of people with chronic low back pain, Physiotherapy 103: 160-166.

Waddell, G. \& Burton, A.K. 2005, Concepts of rehabilitation for the management of low back pain, Best Practice \& Research Clinical Rheumatology 19: 655-670.

Waddell, G. 2004, The back pain revolution, 2nd edn, Churchill Livingstone, Edinburgh.

Waddell, G. 1987, 1987 Volvo award in clinical sciences. A new clinical model for the treatment of low-back pain, Spine 12: 632. 
Waddell, G., McCulloch, J.A., Kummel, E. \& Venner, R.M. 1980, Nonorganic physical signs in low-back pain, Spine 5: 117.

Wallden, M. 2015, "But we're infinitely more complex than a car": A systems approach to health \& performance, Journal of bodywork and movement therapies 19: 697.

Weaver, K., Mitcham, C. 2008, Nursing concept analysis in North America: state of the art, Nursing Philosophy 9: 180-194.

Wijma, A.J., Bletterman, A.N., Clark, J.R., Vervoort, Sigrid C J M, Beetsma, A., Keizer, D., Nijs, J., van Wilgen, C.P. 2017, Patient-centeredness in physiotherapy: What does it entail? A systematic review of qualitative studies, Physiotherapy Theory and Practice 33: 825.

Wijma, A.J., van Wilgen, P. C., Meeus, M., Nijs, J. 2017, Response to Letter. Physiotherapy Theory and Practice 33: 263-265.

Wijma, A.J., van Wilgen, C.P., Meeus, M., Nijs, J. 2016, Clinical biopsychosocial physiotherapy assessment of patients with chronic pain: The first step in pain neuroscience education, Physiotherapy theory and practice, 32: 368-384. 
Tables and Figures

Table 1. Definitions of antecedents, consequences and attributes

\begin{tabular}{|l|l|}
\hline Terminology & Definition \\
\hline Antecedents & Behaviours, thoughts and events that preceded the concept \\
\hline Consequences & Resultant outcomes of the concept \\
\hline Attributes & $\begin{array}{l}\text { Frequently occurring words that are used to describe the } \\
\text { concept }\end{array}$ \\
\hline
\end{tabular}

\section{Table 2. Surrogate terms reflected as key search terms}

bio-psychosocial ${ }^{*} /$ holistic $^{*} /$ patient-centered ${ }^{*} /$ patient-centred $* /$ patient centered $*$ patient centred $*$ person-centered ${ }^{*} /$ person-centred ${ }^{*} /$ person centered ${ }^{*} /$ integration model/ relationship-centered $*$ relationship centered $*$ mind-body connection*/ mind body connection*

Key: * - truncation to allow for biopsychosocial, holistic, mind-body connection model/ approach/ framework/ focus/ orientation and patient or person centered/ centeredness.

\section{Table 3. Eligibility Criteria}

Inclusion Criteria

Biopsychosocial is the focus of the article (one or more of the following):

- A justification or analysis of the use and implementation of the BPSM is offered.

- Literature that focus on physiotherapists' understanding, experiences and perspectives of the BPSM.

- Antecedents, consequences and attributes of the BPSM are provided (one or more of these).

Context of the literature relates to physiotherapy practice

Conceptual, and / or theoretical elements of the BPSM within physiotherapy are discussed All years accepted

The literature is published in English

The literature is peer reviewed 
Table 4. Thematic analysis (Braun and Clarke, 2006)

\begin{tabular}{|l|l|}
\hline \multicolumn{2}{|l|}{ Six phase method of thematic analysis } \\
\hline 1. & Familiarisation with the data \\
\hline 2. & Generating initial codes \\
\hline 3. & Searching for themes \\
\hline 4. & Reviewing themes \\
\hline 5. & Defining-redefining and naming themes \\
\hline 6. & Producing the report \\
\hline
\end{tabular}

Table 5. An example from data analysis: the construction of the 'Failure of biomedical model' antecedent of the BPSM concept.

\begin{tabular}{|c|c|c|}
\hline $\begin{array}{l}\text { Meaning units (excerpts from retrieved } \\
\text { documents) }\end{array}$ & $\begin{array}{l}\text { Words and phrases standing } \\
\text { for the antecedents }\end{array}$ & $\begin{array}{l}\text { Defining } \\
\text { antecedent }\end{array}$ \\
\hline $\begin{array}{l}\text { BMM does not explain chronic pain. } \\
\text { Evidence shows treatment of chronic pain } \\
\text { needs to include self-efficacy, } \\
\text { depression, pain catastrophising and } \\
\text { physical activity. Treatment focussed on } \\
\text { a biomedical approach in low back pain is } \\
\text { a risk factor for long-term sick leave, (Nijs } \\
\text { et al, 2013). }\end{array}$ & $\begin{array}{l}\text { Biomedically focused } \\
\text { treatment is insufficient. } \\
\text { BMM does not explain } \\
\text { complex pain. }\end{array}$ & $\begin{array}{l}\mathrm{BMM} \text { is } \\
\text { inadequate }\end{array}$ \\
\hline $\begin{array}{l}\text { Treatments need to be based around the } \\
\text { patient's perspectives; importance on the } \\
\text { physical, cognitive, affective and socio- } \\
\text { occupational factors prompting a } \\
\text { theoretical model shift in physiotherapy } \\
\text { (Sanders et al, 2013). }\end{array}$ & $\begin{array}{l}\text { BMM is failing. } \\
\text { A shift away from the BMM is } \\
\text { needed. }\end{array}$ & $\begin{array}{l}\text { Failure of } \\
\text { BMM }\end{array}$ \\
\hline $\begin{array}{l}\text { Biomedical style of undergraduate } \\
\text { training can increase negative beliefs and } \\
\text { attitudes about LBP (Domenech et al, } \\
\text { 2011). }\end{array}$ & BMM training can be harmful. & $\begin{array}{l}\text { Failure of } \\
\text { BMM }\end{array}$ \\
\hline
\end{tabular}




\section{Figure 1. Flow diagram of article search strategies and selection}

* Secondary and tertiary searches involved a snowballing search strategy (Jesus, Bright, Kayes and Cott, 2016; Greenhalgh and Peacock 2005).

* On a further quaternary snowballing search of the reference lists of the final two articles, no titles were appropriate for selection.

\section{Primary database search}

Confined to 2012-2017:

Total hits: 2,170

Titles and abstracts selected for screening:

$$
\text { ( } n=89)
$$

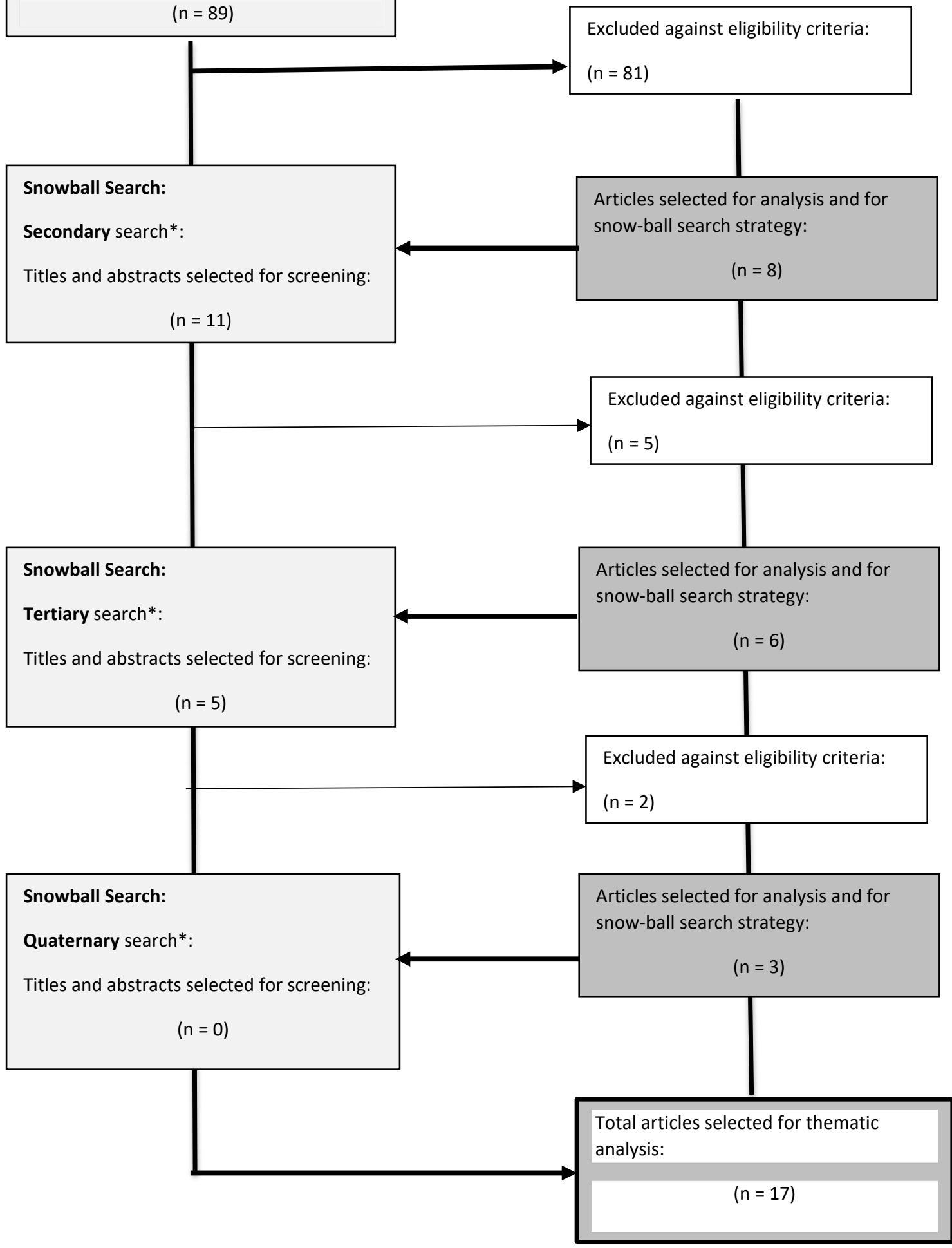


Figure 2. An overview of antecedents, attributes and consequences of the concept of the biopsychosocial model in musculoskeletal physiotherapy.

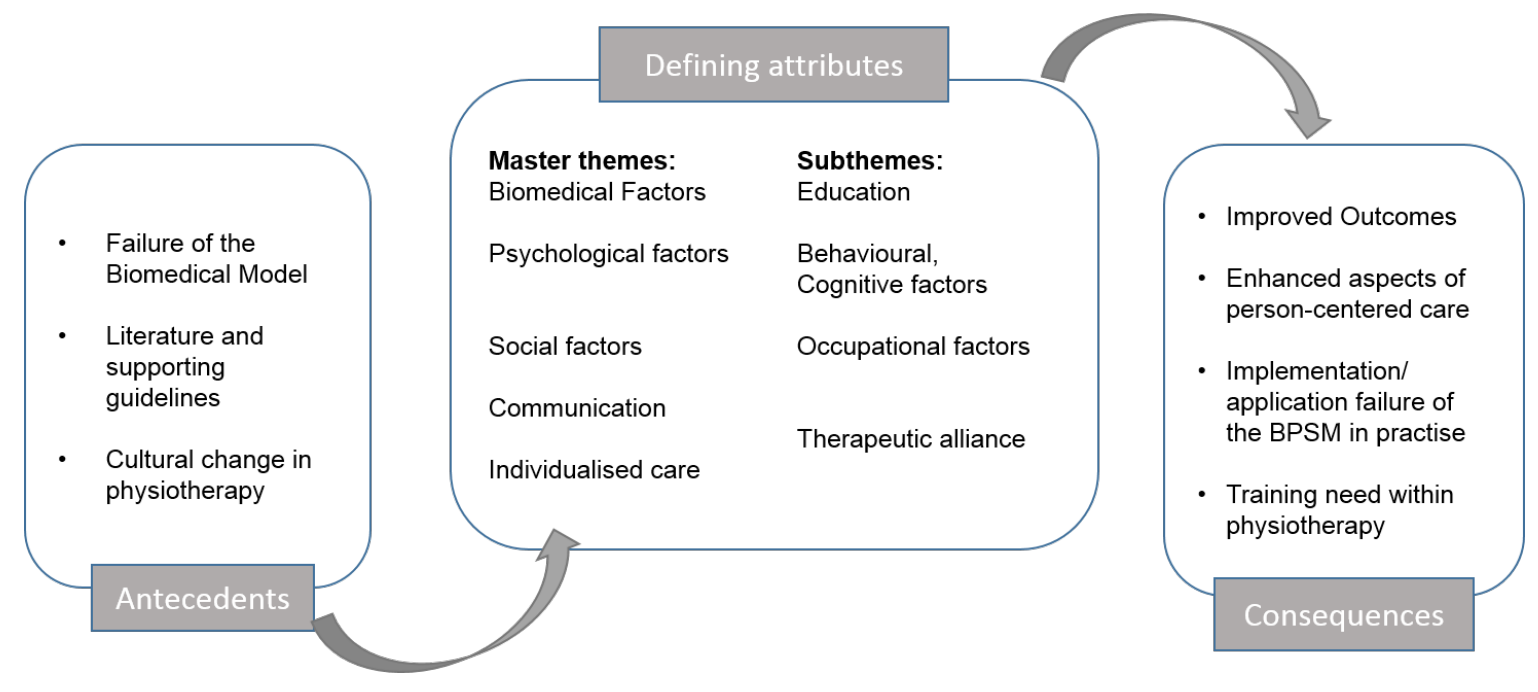

Figure 3. Conceptual map of the Master theme 'BIOMEDICAL' and Subtheme 'Education'

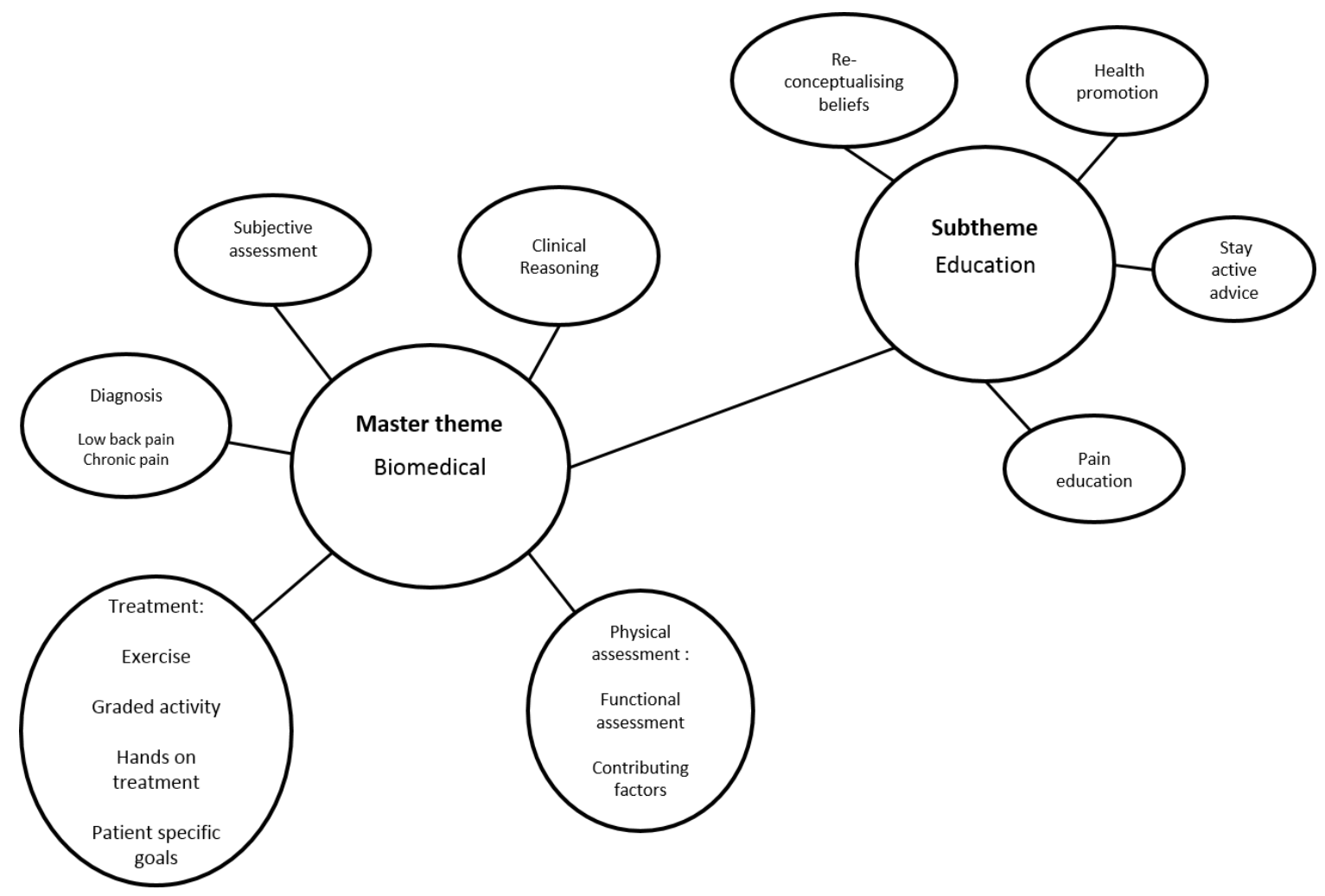


Figure 4. Conceptual maps of master theme Psychological Factors and subthemes Cognitive Factors and Behavioural Factors'

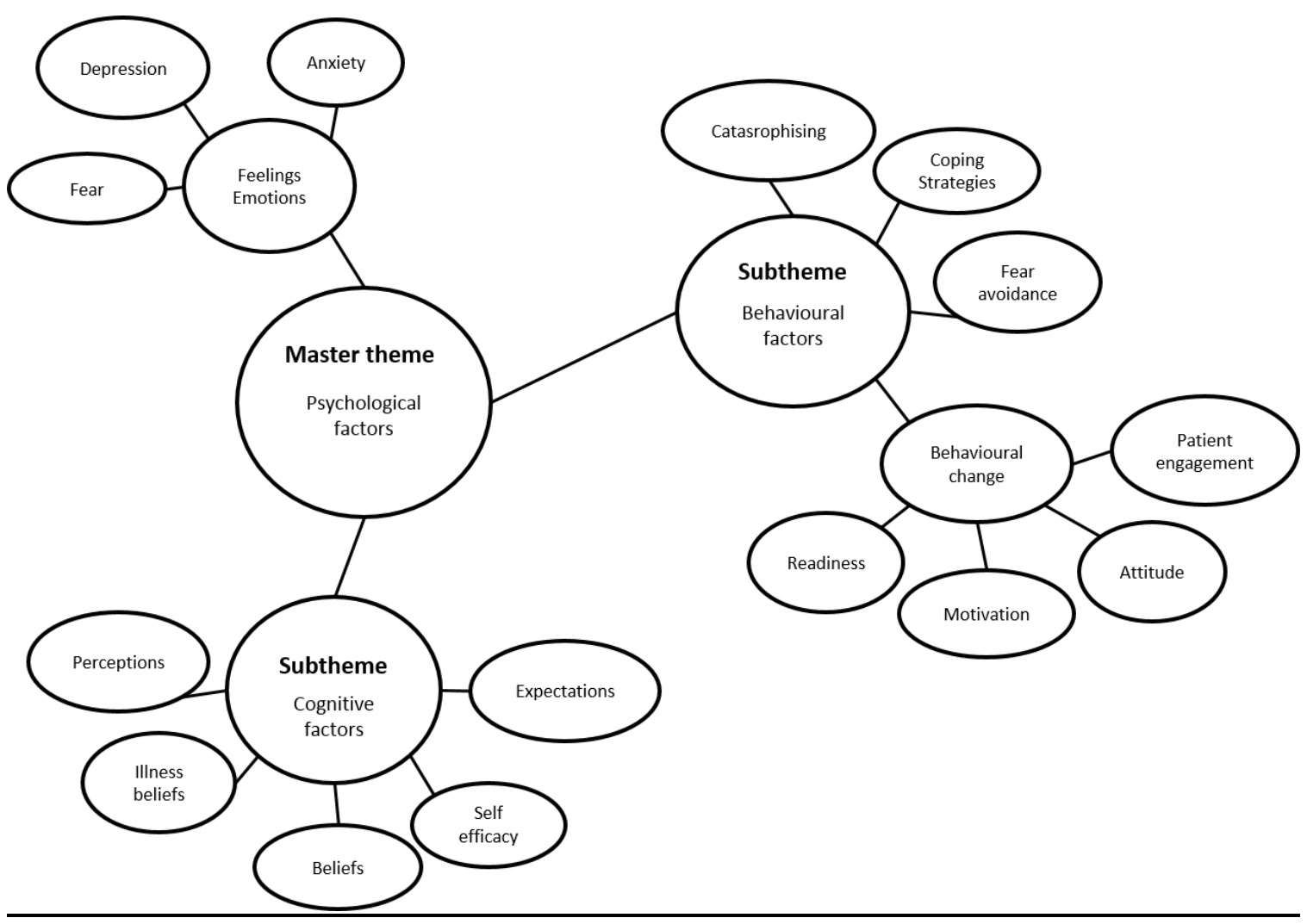

Figure 5. Conceptual map of master theme Social Factors and subtheme Occupational Factors.

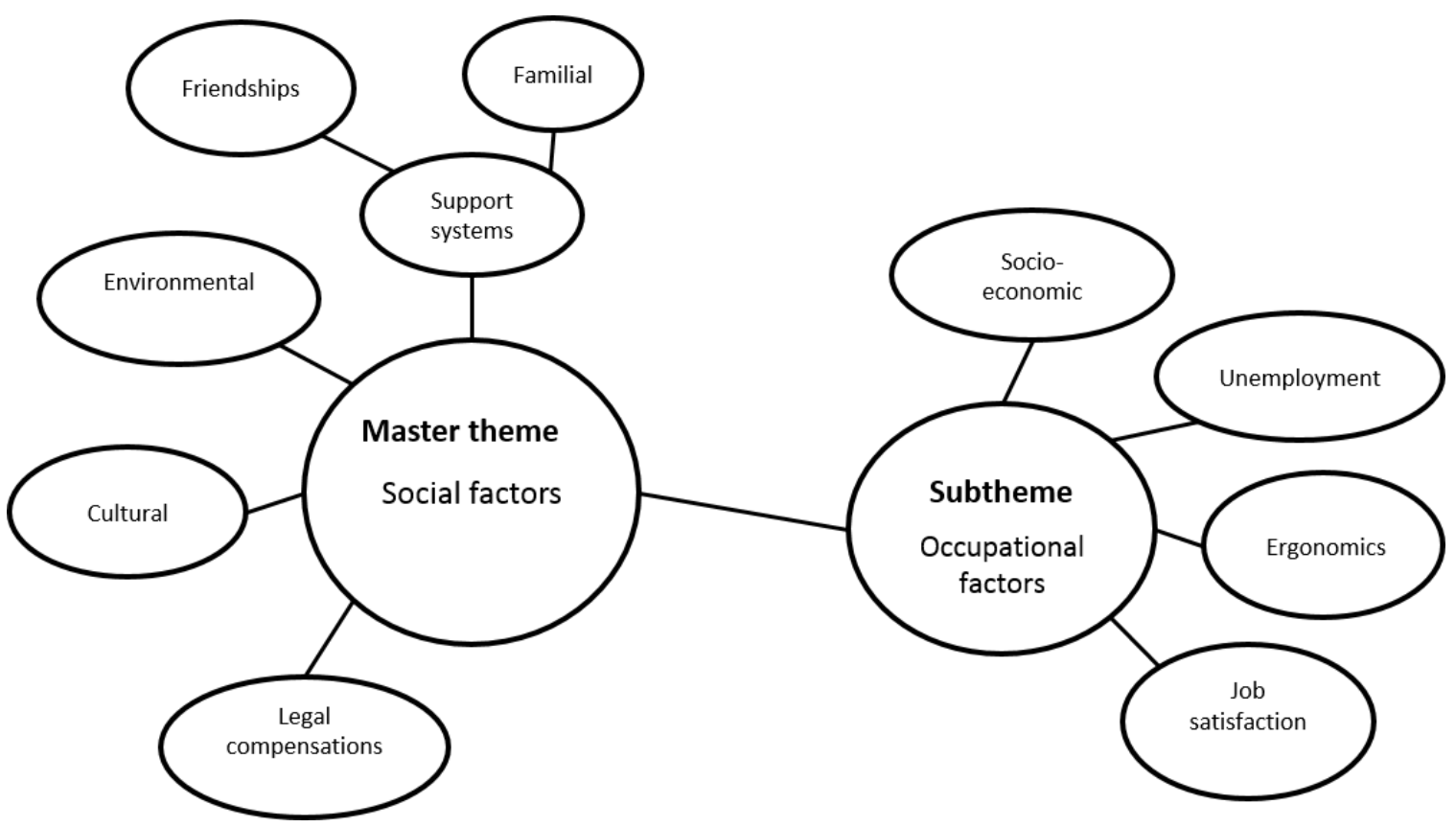


Figure 6. Conceptual map of master theme Communication and Individualised Care connecting to create the subtheme Therapeutic Alliance

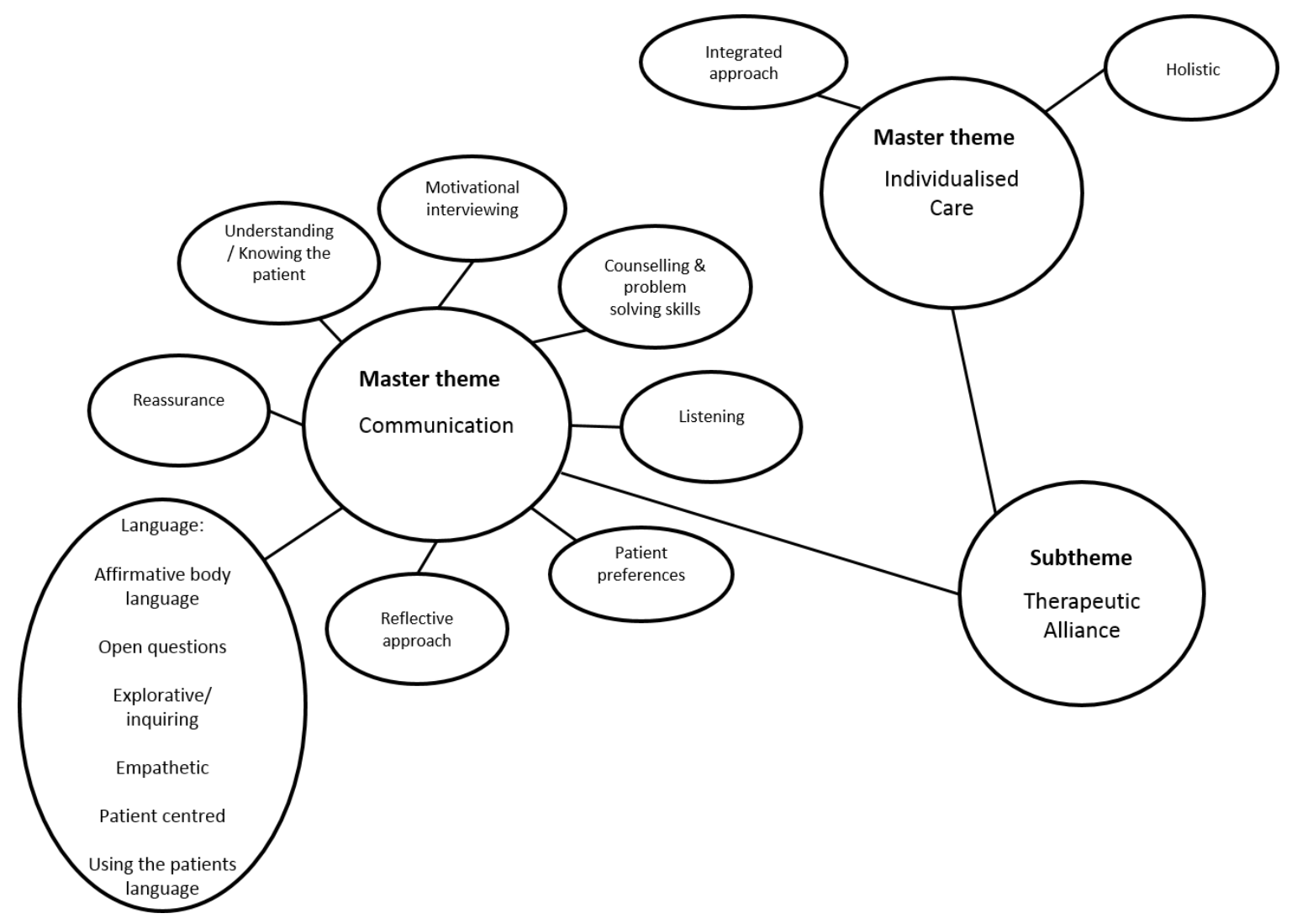

Figure 7. Traditional Venn diagram of the BPSM

\section{Biological}

\section{Sociocultural}

Psychological 
Figure 8. Reconstructed Venn diagram for the BPSM

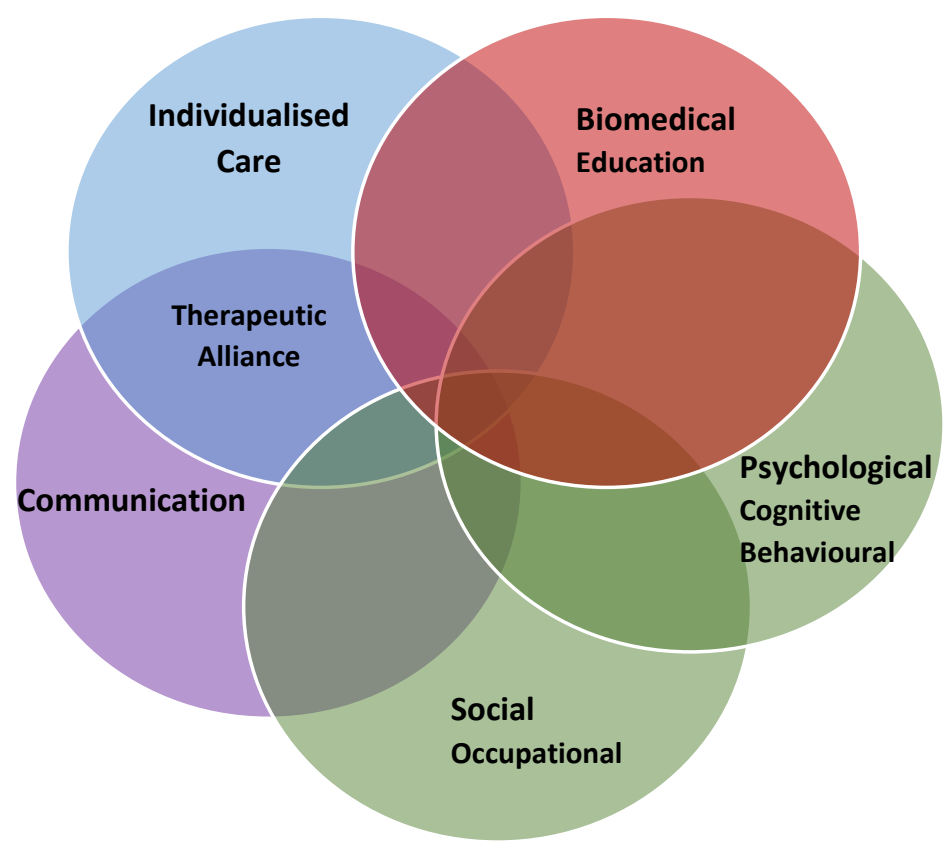


Figure 9. Proposed Holistic framework for practice based on concept analysis of the Biopsychosocial model in musculoskeletal physiotherapy. The helix, comprised of communication and therapeutic alliance allows an exploration of the biomedical, psychological (cognitive, behavioural), social (occupational elements), respecting the sharing of lifeworlds that together enable more individualised, person centred, holistic care.

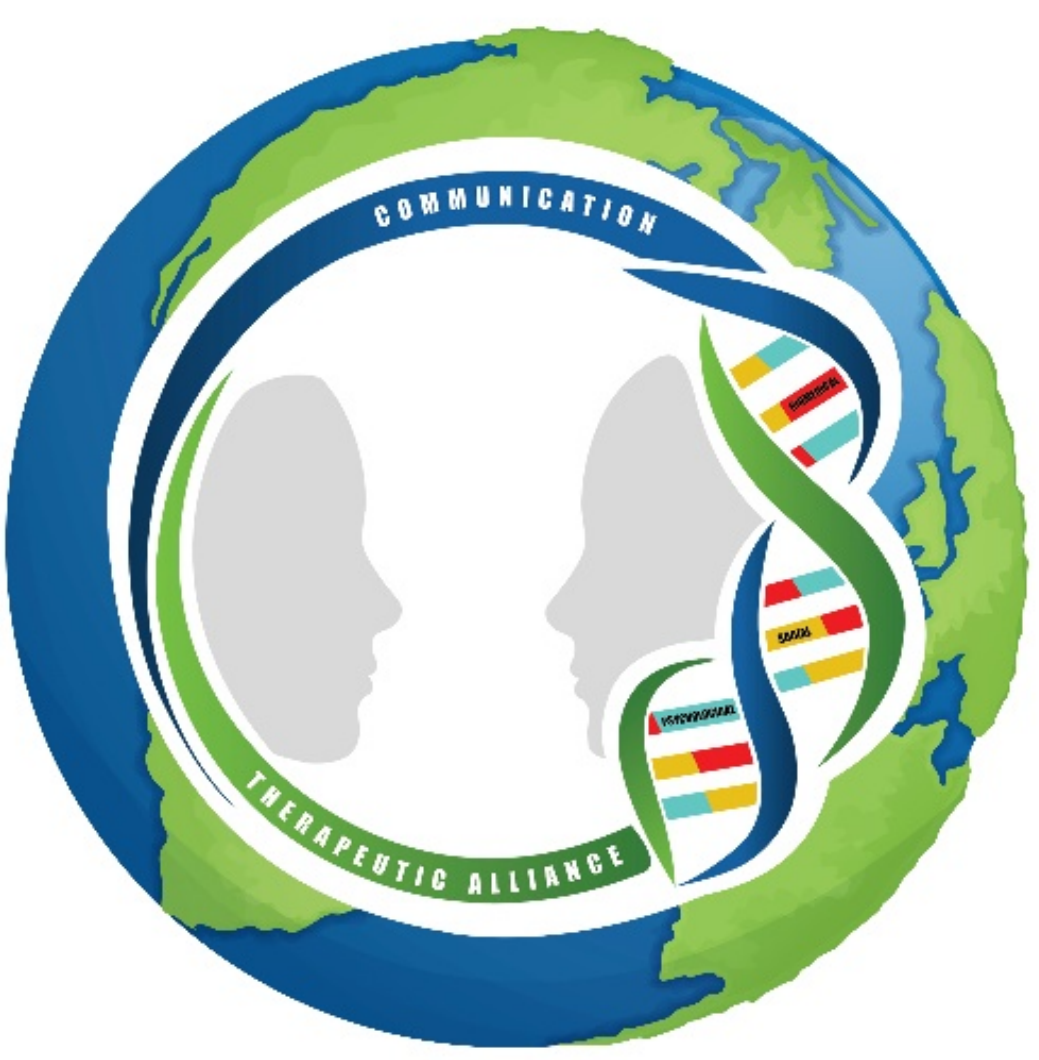

